\title{
Relation of Age and Serum Prostatic-Specific Antigen level with Histopathologicaldiagnosisin Transurethral Resection of Prostate specimen, an Experience from Eastern Tertiary Hospital
}

\author{
Shah $\mathrm{RS}^{1}$, Panday $\mathrm{DR}^{2}$
}

\begin{abstract}
Background:Prostatic Specific Antigen (PSA) is a protease secreted by epithelial cells of prostate. Serum PSA level is increased when the normal structure of gland is destroyed by benign or malignant tumor or inflammation. Though there is established relation between PSA plasma level and age among the two most common prostate diseases (Benign prostatic hyperplasia and Carcinoma Prostate) in the literature, relation has not been explored in our part of the world, therefore, this study was done to see the relation between age and PSA amount with Prostate diseases. Material and Methods: This was a Cross-sectional study conducted in a tertiary hospital, Nobel Medical College Teaching Hospital from January 2017 to December 2018 . Ethical clearance was obtained from Institutional Review Committee (IRC). All the cases of prostate diseases presenting to urology department undergoing transurethral resection of the prostate (TURP) were included. Histopathologyreport of TURP specimenwere collected from department of pathology and the relationshipbetween diagnosis, PSA level and age were established.Results:BPH was the most common diagnosis (72.41\%). Age of BPH patients ranged from 48-78 years and mean age with SD was 60.56 \pm 7.32 . Median age with interquartile range was 61.00. Similarly, in the BPH group, PSA value ranged between 0.80-15.40 ng/ml with mean PSA value along with SD being $5.64 \pm 4.16 \mathrm{ng} / \mathrm{ml}$. Similarly, Median PSA value with interquartile range was $4.20 \mathrm{ng} / \mathrm{ml}$. Carcinoma Prostate (27.59\%) was the second most common diagnosis. Histological type of all cases diagnosed as cancer was adenocarcinoma. Their age ranged between 54-83. Their mean age with SD was 67.67 \pm 7.68 . Similarly, Median age with interquartile range was 68.00 . PSA value in this group ranged between $8.50-147.30 \mathrm{ng} / \mathrm{ml}$. Again, the mean PSA value with SD is $55.72 \pm 33.40 \mathrm{ng} / \mathrm{ml}$. Similarly, Median PSA value with interquartile range is $54.30 \mathrm{ng} / \mathrm{ml}$.Conclusion: PSA level in the blood of men over 40years is highly correlated with a Age, irrespective of diagnosis. In above 40 age group, with advancing age, Carcinoma Prostate becomes more and more common diagnosis than BPH. Similarly, average PSA level is higher in Carcinoma Prostate than BPH.
\end{abstract}

\section{Keywords:Benign prostatic hyperplasia (BPH), Prostatic Neoplasms, Prostate specific antigen(PSA)}

1. Dr. Ram Sagar Shah

2. Dr. Dipesh Raj Pandey

Address for Correspondence:

\author{
Dr. Ram Sagar Shah \\ Department of Urology \\ Nobel Medical College Teaching Hospital \\ Biratnagar, Nepal \\ Email: ramsagarshahsurgeon@gmail.com
}

\section{INTRODUCTION}

Prostatic Specific Antigen(PSA) is a serine protease which is secreted by epithelial cells of prostate.Blood level of PSA is increased when the normal structure of gland is destroyed by either benign or malignant tumor or inflammation ${ }^{1}$. Therefore, PSA as a marker for early detection and monitoring of patients with Carcinoma Prostate is being widely used ${ }^{2}$.Immunoassay is used to measure the serum samples of PSA ${ }^{3}$.

Discovered by Wang et al. in 1979,PSA has had a strong impact in the management of patients with Carcinoma Prostate. Despite the serum levels of PSA greater than $4 \mathrm{ng} / \mathrm{ml}$ by hybritech assay are compatible with Carcinoma Prostate; it can also be elevated from the normal value in benign prostatic hyperplasia. Moreover, patients who present with values between 4 and 10 pose a clinical puzzle ${ }^{4}$.

Carcinoma prostate is the second mostcommon malignancy in the men.Patients with Carcinoma Prostate are generally asymptomatic at the early stage but may present with difficulty with urination, increased frequency of urination and nocturia. Late stage of disease can present with retention of urine and back pain since vertebra is the commonest site of metastatic disease ${ }^{5}$.Carcinoma Prostate accounts for $9.5 \%$ of all new cancer cases in the USA making it the second most common cancer $^{5}$. Relatively, Asians have lowest rates especially Chinese, and the highest rates are found among the North-American and Scandinavian especially African- Americansof USA ${ }^{6}$.

Benign prostatic hyperplasia (BPH) presents with prostate enlargement and lower urinary tract symptoms (LUTS). It cannot be escaped by the ageing male population. However, not all patients with BPH develop LUTS and not all patients with LUTS have $\mathrm{BPH}^{7}$. Area of prostate which is most vulnerable to develop $\mathrm{BPH}$ is periurethral transitional zones ${ }^{8}$. Age, prostate volume, and serum prostate specific antigen (PSA) level are some useful parameters to identify progression of $\mathrm{BPH}^{9}$.

Though there is established relation between PSA plasma level and age among the two most common prostate diseases (BPH and Carcinoma Prostate) in the literature, relation has not 
been explored in our part of the world, therefore, this study was done to see the relation between age and PSA amount with Prostate diseases.

\section{MATERIALS AND METHODS}

This was a Cross-sectional study conducted in a tertiary hospital, Nobel Medical College Teaching Hospital from January 2017 to December 2018. Ethical clearance to carry out the study was obtained from Institutional Review Committee (IRC) of the institute. Patients were enrolled after giving consent. The patients diagnosed to have prostate disease earlier than presentation or those on allopathic drugs for any Prostate disease were excluded from the study. Additionally, patients with histological diagnosis other than $\mathrm{BPH}$ or Carcinoma Prostate were also excluded. Only those aging 40 or above with LUTS (Lower Urinary Tract Symptoms) were included in the study. All the cases of prostate disease presenting to Urology department and undergoing Transurethral Resection of Prostate (TURP) during the study period fit the eligibility criteria and were included in the study. Blood samples were taken just before TURP and at least one week after digital rectal examination to avoid possible errors caused by the release of PSA from the prostate. The serum samples were stored at $-20 \stackrel{\circ}{ } \mathrm{C}$ and were tested for PSA. PSA was estimated by ELISA technique using high affinity Biotin-Streptavidin system, with analytical sensitivity of $0.05 \mathrm{ng} / \mathrm{mL}$ (HUMAN, Germany). The tissue samples collected after TURP were sent to department of Pathology for evaluation. These biopsies were fixed overnight in $10 \%$ formalin, processed in automatic tissue processor (Yorco) and paraffin blocks were prepared. Paraffin embedded sections were stained with Hematoxylin and Eosin ( $\mathrm{H}$ and $\mathrm{E}$ ) for histopathological examination and diagnosis. Histopathology report of TURP specimen were collected from Department of Pathology and the relationship between diagnosis, PSA level and age were found out. Data was entered in Microsoft excel sheet (office 2016) analyzed using the statistical software package SPSS 11.5 (Statistical Package for Social Science) for Windows. Associations between different diagnostic categories and PSA were tested with chi square test and correlation where appropriate. P-value $<0.05$ was considered as statistically significant.

\section{Sample size calculation}

Total sample size required to determine whether a correlation coefficient differs from zero ${ }^{10}$.

The standard normal deviate for $\alpha=Z_{\alpha}=1.960$

The standard normal deviate for $\beta=Z_{\beta}=0.842$

$C=0.5 * \ln [(1+r) /(1-r)]=0.292$

Total sample size $=\mathrm{N}=\left[\left(\mathrm{Z}_{\alpha}+\mathrm{Z}_{\beta}\right) / \mathrm{C}\right]^{2}+3=95$

\section{RESULT}

Overall, there were 116 patients with age ranging from 48 to 83 years. Their mean age in years with standard deviation (SD) was $62.52 \pm 8.04$. The median age with interquartile range in years was 62 (57-68). All of them underwent PSA detection and histopathological examination. Their PSA value ranged from 0.80 to $147.30 \mathrm{ng} / \mathrm{ml}$. The mean PSA value with SD was $19.45 \pm 28.61 \mathrm{ng} / \mathrm{ml}$. The median PSA value with interquartile range was $7.05(3.0-17.42) \mathrm{ng} / \mathrm{ml}$.

A positive correlation (Spearman's rho=0.775; $p$-value $<0.001$ ) between Age and PSA (Figure 1) was found.

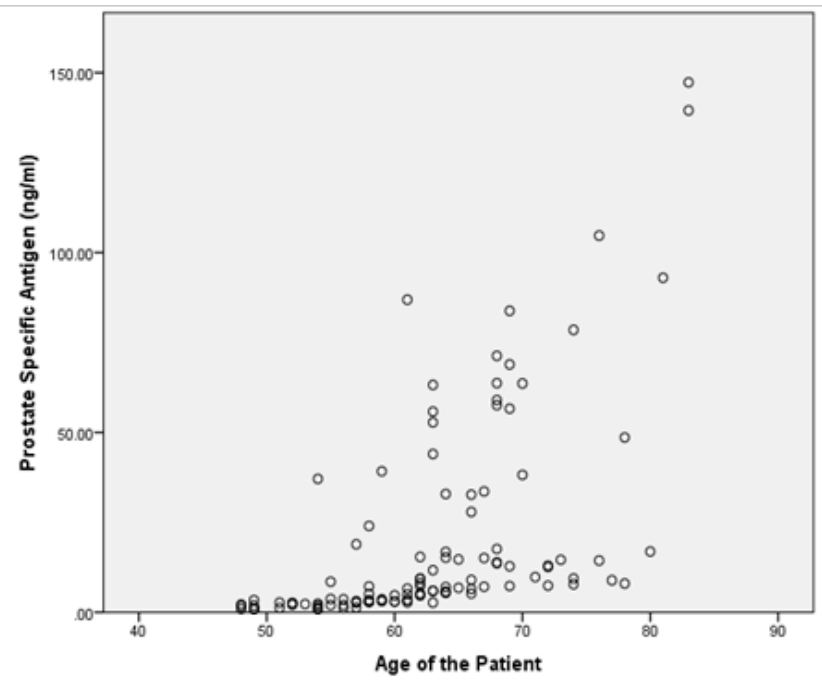

Figure 1: Scatter-plot diagram showing correlation between age of the Patient and PSA level overall

On histopathologicalexamination, BPH was the most common diagnosis ( $n=84 ; 72.41 \%$ ). Age of $\mathrm{BPH}$ patients ranged from 48-78 years and mean age with SD was $60.56 \pm 7.32$ years. Median age with interquartile range was 61.00 (55.25$64.75)$ years. Similarly, in the BPH group, PSA value ranged between $0.80-15.40 \mathrm{ng} / \mathrm{ml}$ with mean PSA value along with SD being $5.64 \pm 4.16 \mathrm{ng} / \mathrm{ml}$. Similarly, median PSA value with interquartile range was $4.20(0.80-15.40) \mathrm{ng} / \mathrm{ml}$.Asignificant positive correlation (Spearman's rho $=0.872$; p-value $<0.001$ ) between Age and PSA (Figure: 2) was observed in BPH group.

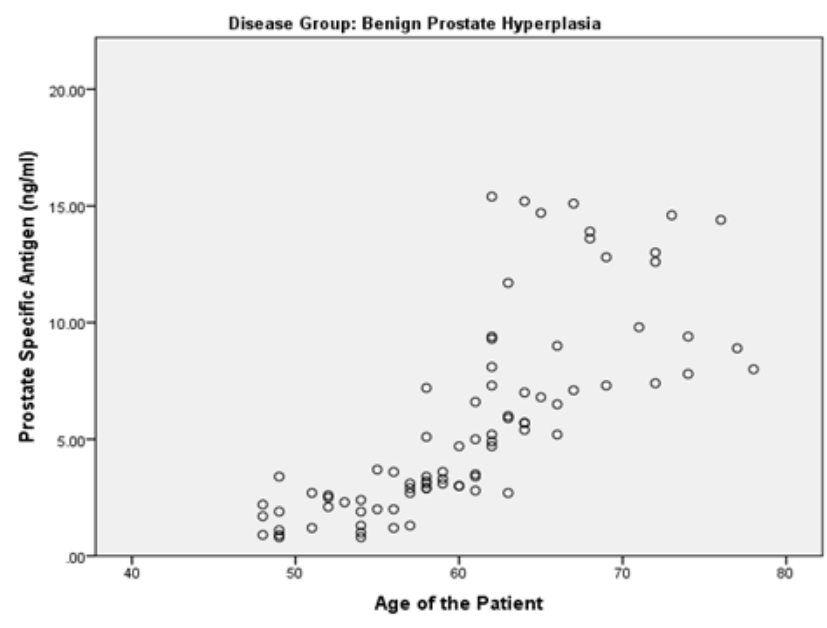

Figure 2: Scatter-plot diagram showing correlation between age of the Patient and PSA level in BPH group. 
Carcinoma Prostate ( $n=32 ; 27.59 \%)$ was the second most common diagnosis. Histological type of all cases diagnosed as cancer was adenocarcinoma. Their age ranged between 54-83 years. Their mean age with SD was $67.67 \pm 7.68$ years. Similarly, median age with interquartile range was 68.00 (63-70) years. PSA value in this group ranged between $8.50-147.30 \mathrm{ng} / \mathrm{ml}$. The mean PSA value with SD is $55.72 \pm 33.40 \mathrm{ng} / \mathrm{mlandmedian}$ PSA value with interquartile range is 54.30 (32.75-70.70) ng/ $\mathrm{ml}$.Carcinoma Prostate group also showedsignificant positive correlation (Spearman's rho=0.539; p-value $<0.001$ ) between Age and PSA (Figure 3).

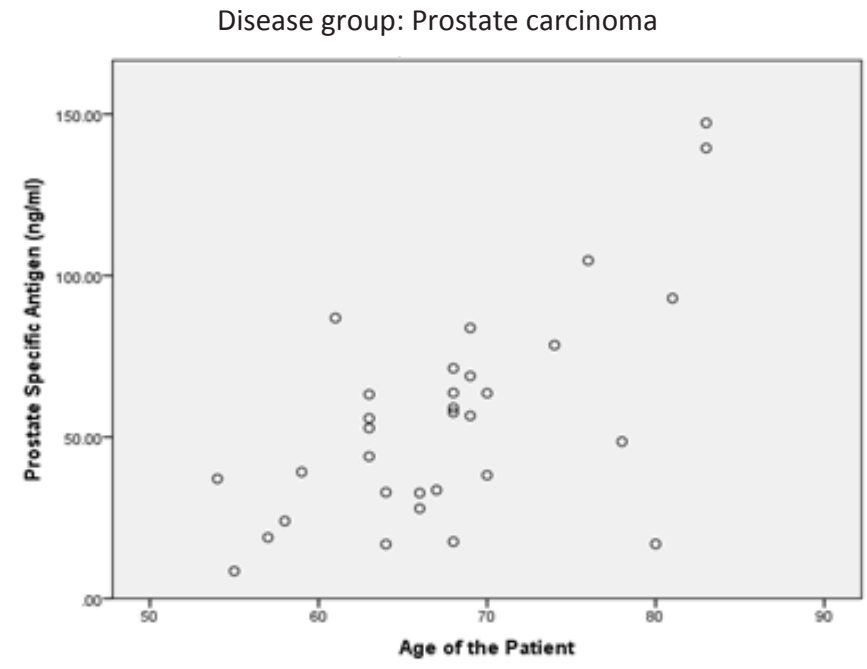

Figure 3: Scatter-plot diagram showing correlation between age of the Patient and PSA level in Carcinoma Prostate group

In either cases, common symptoms were urinary obstruction, frequency of micturition, nocturia and hesitancy.

The association between different diagnostic groups as determined by histopathological findings of prostate and age or PSA ranges were statistically significant $(p<0.001$, Table I and Table II).

\begin{tabular}{|c|c|c|c|c|}
\hline \multicolumn{5}{|c|}{ Disease } \\
\cline { 1 - 4 } Age groups & $\begin{array}{c}\text { Benign prostatic } \\
\text { hyperplasia }\end{array}$ & $\begin{array}{c}\text { Prostate } \\
\text { carcinoma }\end{array}$ & Total & p-value \\
\hline $41-50$ & $8(9.5 \%)$ & $0(0 \%)$ & 8 & \\
\cline { 1 - 4 } $51-60$ & $30(35.7 \%)$ & $5(15.6 \%)$ & 35 & \multirow{2}{*}{$<0.001$} \\
\cline { 1 - 4 } $61-70$ & $36(42.9 \%)$ & $18(56.3 \%)$ & 54 & \\
\cline { 1 - 3 } $71-80$ & $10(11.9 \%)$ & $5(15.6 \%)$ & 15 & \\
\cline { 1 - 3 }$>>80$ & $0(0 \%)$ & $4(12.5 \%)$ & 4 & \\
\cline { 1 - 3 } Total & $84(100 \%)$ & $32(100 \%)$ & 116 & \\
\hline
\end{tabular}

Table l: Comparison of age groups of patients with histopathological findings of prostate using chi-square test

\begin{tabular}{|c|c|c|c|c|}
\hline \multicolumn{5}{|c|}{ Disease } \\
\hline $\begin{array}{l}\text { Prostate specific } \\
\text { antigen (ng/ml) }\end{array}$ & $\begin{array}{c}\text { Benign } \\
\text { prostatic } \\
\text { hyperplasia }\end{array}$ & $\begin{array}{l}\text { Prostate } \\
\text { carcinoma }\end{array}$ & Total & p-value \\
\hline$<4$ & 42 (50\%) & $0(0 \%)$ & 42 & \multirow{6}{*}{$<0.001$} \\
\hline $4-10$ & 30 (35.7\%) & $1(3.1 \%)$ & 31 & \\
\hline $11-20$ & $12(14.3 \%)$ & $4(12.5 \%)$ & 16 & \\
\hline $21-50$ & $0(0 \%)$ & $10(31.3 \%)$ & 10 & \\
\hline$>50$ & $0(0 \%)$ & $17(53.1 \%)$ & 17 & \\
\hline Total & 84 (100\%) & 32 (100\%) & 116 & \\
\hline
\end{tabular}

Table II: Comparison of prostate specific antigen of patients with histopathological findings of prostate using chi-square test

In our study sample, PSA level above $20 \mathrm{ng} / \mathrm{ml}$ was diagnostic of Prostate Carcinoma and similarly Prostate disease below 4 $\mathrm{ng} / \mathrm{ml}$ was BPH

\section{DISCUSSION}

Literature shows that $\mathrm{BPH}$ is one of the most common diseases of older men, with more than $70 \%$ of men over 70 years affected, and prostate cancer is one of the most common cancer in men ${ }^{11,12}$.In our study, similar to the works done in different parts of India, most BPH patients were in the age range of 61-70 years and so were the cases of Prostate Carcinoma ${ }^{13}$. This finding is also in line with with another study done in Kathmandu valley ${ }^{14}$.

In our study sample those below 50 years, independent of PSA level, had no Carcinoma Prostate (Table I).The median age for Carcinoma Prostate is 68 years ${ }^{14}$. On the other end of spectrum, anyone above 80 years with LUTS that have undergone TURP, independent of PSA level, were found to have Prostate Carcinoma whereas, no such patient was diagnosed of having $\mathrm{BPH}$. Most studies show that $\mathrm{BPH}$ develops earlier than Carcinoma Prostate ${ }^{15}$. In our study it is seen that BPH develops earlier (mean age: 60.56 \pm 7.32 ) than Carcinoma Prostate (mean age: 67.67 \pm 7.68 ). It was similar in most studies ${ }^{13,16,17}$.

All cases having PSA level below4ng/ml were later diagnosed to have BPH, and all patients with PSA level above $20 \mathrm{ng} / \mathrm{ml}$, were diagnosed Prostate Carcinoma. These findings were similar to the studies done by the researchers elsewhere ${ }^{1,9,13,14,16,17,18 . O u r}$ study also points at the fact that BPH has lower level of PSA (mean $=5.64 \pm 4.16 \mathrm{ng} / \mathrm{ml}$ ) compared to Carcinoma Prostate (mean=55.72 $\pm 33.40 \mathrm{ng} / \mathrm{ml}$ ) similar to other studies ${ }^{18,19}$.

We found significant positive correlation between age and PSA level, irrespective of the diagnosis, with strongest correlation in $\mathrm{BPH}$ group. However, in a Turkish study, no significant correlation was found between serum PSA levels and age. It might be because age-range was more broad in that study ${ }^{20}$.

This study is first of its kind from Eastern part of Nepal, which reflects local scenario of Prostate disease (Histopathological dichotomy into Prostate Carcinoma and $\mathrm{BPH}$ ) and its relation 
with age and PSA level. Since the populations in the developing countries like ours are aging, males over 40 should have their PSA level regularly checked, especially if there are features of LUTS or family history of Prostate disease or symptoms. Government should initiate PSA screening programs among the aged malewith a priority to catch the disease in early curable state. Our finding is a single center experience. To extrapolate the findings, bigger multicentric (multi-state and multi-regional) studies should be contemplated.

Our work has some correctable limitations namely;

i) Associated conditions of Prostate that can independently influence PSA levels like inflammation, acute retention of urine were not taken into account.

ii) Histologic evaluation was done on TURP specimens and not prostatectomy specimens.

\section{CONCLUSION}

PSA level in the blood of men over 40 is highly correlated with Age, irrespective of diagnosis. In above 40 age group, with advancing age, Carcinoma Prostate becomes more and more common diagnosis than BPH. Similarly, average PSA level is higher in Carcinoma Prostate than BPH.

\section{REFERENCES}

1. Gann PH, Hennekens $\mathrm{CH}$, Stampfer MJ. A Prospective Evaluation of Plasma Prostate-Specific Antigen for Detection of Prostatic Cancer. JAMA J Am Med Assoc. 1995; 273: 289-94.

2. Nadler RB, Humphrey PA, Smith DS, Catalona WJ, Ratliff TL. Effect of Inflammation and Benign Prostatic Hyperplasia on Elevated Serum Prostate Specific Antigen Levels. J Urol. Ovid Technologies (Wolters Kluwer Health) 1995; 407-13.

3. Carter HB, Pearson JD, Metter EJ, Brant LJ, Fozard JL. Longitudinal Evaluation of Prostate-Specific Antigen Levels in Men With and Without Prostate Disease. JAMA J Am Med Assoc. 1992; 267: 2215-20.

4. Benson MC, Ihn Seong Whang, Pantuck A, Ring K, Kaplan SA, Olsson CA, Cooner WH. Prostate specific antigen density: A means of distinguishing benign prostatic hypertrophy and prostate cancer. J Urol. 1992; 147: 815-6.

5. Rawla P. Epidemiology of Prostate Cancer. - PubMed - NCBI. World J Oncol. 2019;10:63-89.

6. Grönberg H. Prostate cancer epidemiology. Lancet. Elsevier Limited. 2003; 361: 859-64.

7. Lim K Bin. Epidemiology of clinical benign prostatic hyperplasia. Asian Journal of Urology. Editorial Office o Asian Journal of Urology. 2017: 148-51.

8. Briganti A, Capitanio U, Suardi N, Gallina A, Salonia A, Bianchi M, Tutolo M, Di Girolamo V, Guazzoni G, Rigatti P Montorsi F. Benign Prostatic Hyperplasia and Its Aetiologies. European Urology, Supplements. 2009: 865-71.

9. Xia SJ, Cui D, Jiang $Q$. An overview of prostate diseases and their characteristics specific to Asian men. Asian Journal of Andrology. 2012: 458-64.

10. Hulley SB, Cummings SR, Browner WS, Grady D, Newman TB. Designing clinical research :an epidemiologic approach. 4th ed. Philadelphia, PA: Lippincott Williams \& Wilkins. 2013: 79.

11. Miah S, Catto J. BPH and prostate cancer risk. Indian J Urol. Medknow Publications. 2014: 214-8.
12. Chang RTM, Kirby R, Challacombe BJ. Is there a link between BPH and prostate cancer? Practitioner. 2012:13-6.

13. Jayapradeep DP, Prakash VB, Philipose TR, Pai MR. Histomorphologic Correlation of PSA Levels in Prostatic Pathology. Natl J Lab Med. 2017;6: 28-32.

14. Hirachand S, Dangol UMS, Pradhanang S, Acharya S. Study of prostatic pathology and its correlation with prostate specific antigen level. J Pathol Nepal. 2017; 7: 1074-7.

15. Gupta S, Gupta A, Saini AK, Majumder K, Sinha K, Chahal A. Prostate cancer: How young is too young? CurrUrol. S. Karger AG. 2017; 9: 212-215.

16. Prcic A, Begic E, Hiros M. Usefulness of total PSA value in prostate diseases diagnosis. Acta Inform Medica. Avicena Publishing. 2016; 24 :156-61.

17. Banerjee B, Iqbal B, Kumar H, Kambale T, Bavikar R. Correlation between prostate specific antigen levels and various prostatic pathologies. J Med Soc. 2016; 30:172-5.

18. Pudasaini S, Subedi N, Shrestha NM. Evaluation of Prostate specific antigen levels and its correlation with histopathological findings. J Pathol Nepal. 2019: 9.

19. Bikkasani K, Kanakmedala S, Sinha S, Siriguri S. Prostate biopsy findings in Indian men: A hospital-based study. Indian J Cancer. 2011;48: 175-80.

20. Rabah DM, Farhat KH, Al-Atawi MA, Arafa MA. Age-specific reference ranges of prostate-specific antigen among saudi men as a representation of the arab population. Med Princ Pract. S. Karger AG. 2019; 28: 242-6. 